\title{
Effects of Combining Diaphragm Training With TENS on Balance, Pain, and Function in Athletes With Chronic Low Back Pain: A Randomized Clinical Trial
}

\section{Khadijeh Otadi}

Department of Physiotherapy, School of Rehabilitation, Tehran University of Medical Sciences

\section{Noureddin Nakhostin Ansari}

Department of Physiotherapy, School of Rehabilitation, Tehran University of Medical Sciences

\section{Shahriar Sharify}

Department of Physiotherapy, School of Rehabilitation, Tehran University of Medical Sciences

\section{Zahra Fakhari}

Department of Physiotherapy, School of Rehabilitation, Tehran University of Medical Sciences

\section{Hadi Sarafraz}

Occupational Medicine Department, Hormozgan University of Medical Sciences, Bandar Abbas, Iran.

\section{Amir Aria}

Prana Physiotherapy Clinic, Tehran, Iran. 3 Department of Public Health and Nursing, Faculty of Medicine and Health Sciences, Norwegian University of Science and Technology, Trondheim, Norway.

\section{Omid Rasouli ( $D$ omid.rasouli@ntnu.no)}

Prana Physiotherapy Clinic, Tehran, Iran. 3 Department of Public Health and Nursing, Faculty of Medicine and Health Sciences, Norwegian University of Science and Technology, Trondheim, Norway. https://orcid.org/0000-0003-2203-1839

\section{Research}

Keywords: Back pain, Diaphragm muscle, Breathing exercises, Electrical stimulation

Posted Date: October 9th, 2020

DOI: https://doi.org/10.21203/rs.3.rs-87776/v1

License: (9) (1) This work is licensed under a Creative Commons Attribution 4.0 International License. Read Full License 


\section{Abstract}

Background: there is a lack of evidence about the effects of diaphragm training combined with TENS on balance, pain, and function in athletes with CLBP.

Objectives: This study aimed to investigate the effects of combining diaphragm training with electrical stimulation on core stability, dynamic balance, pain, and function in young athletes with nonspecific CLBP.

Design: Randomized clinical trial

Method: A total of 24 young adult athletes (12 women, 12 men) with non-specific CLBP were randomly allocated into experimental and control group. The experimental group received diaphragm training plus Transcutaneous Electrical Nerve Stimulation (TENS), while the control group received only TENS. Both groups underwent 12 sessions over a 4-week period. Static stability, dynamic balance, pain, and function were measured pre- and post-intervention.

Results: Significant improvements in pain and function scores were found in both groups after completing the interventions. However, only the experimental group showed significant improvements in the static stability and dynamic balance postintervention. The experimental group showed greater improvements in pain and static stability. No significant differences in function or dynamic balance were observed between the groups.

Conclusions: The present study indicates that diaphragm training plus TENS can improve static stability, dynamic balance, function, and pain in young athletes with non-specific CLBP. It seems beneficial to add diaphragm training to rehabilitation programs for athletes with CLBP.

The trial was retrospectively registered at the Iranian Registry of Clinical Trials on www.irct.ir (Identification number: IRCT20090228001719N8).

\section{Introduction}

Low Back Pain (LBP) in athletes is a common source of pain, and many athletes experience LBP $(1,2)$. The "core" muscles comprise the transversus abdominis and internal oblique, multifidus, diaphragm, and pelvic floor muscles, which provide stability and motor control to the spine (3). The core stability is crucial to correctly perform limb and trunk movements, particularly in athletes (4). Previous research has shown reduced spine stabilization, lumbar segmental instability, and decreased lumbopelvic core muscle control in athletes who suffered from $\operatorname{LPP}(1,5,6)$. The diaphragm muscle is a respiratory muscle with postural function (7). Patients with CLBP are more susceptible to diaphragm fatigue than healthy people and, therefore, need exercise to prevent this fatigue (8). Also, a recent study reported a reduced diaphragm thickness in athletes who suffered from LBP compared to healthy athletes (5). Another study demonstrated that an 8-week diaphragm training was a viable way to increase the thickness not only of the diaphragm but also of other stabilizer muscles of the lumbar spine (9). Therefore, these novel findings indicate that diaphragm training may be an additional useful intervention for athletic performance, prevention, and rehabilitation to improve respiratory capacity, torso stability, and balance, which may consequently reduce the occurrence of $\operatorname{LBP}(5,10-13)$.

Balance is essential for doing everyday activities and enhances physical readiness for better sports performance. Poor scores on balance tests are directly linked to increased injury rates in a healthy athletic population (14). Increasing core stability has been reported to reduce lower back injuries and improve static and dynamic balance in athletes (15). Therefore, strengthening of spinal core muscles is essential to improve and prevent spinal instability in athletic physical performance (16).

Conventional conservative treatment for CLBP focuses on electrotherapy, exercise therapy, and manual therapy (17). Sayilir and Yildizgoren (2017) showed that using TENS for patients with CLBP could lead to reduced pain and improved physical 
functions; hence, they suggested to use TENS as part of the rehabilitation for chronic LBP (18). However, to our knowledge, there is a lack of evidence about the effects of diaphragm training combined with TENS on balance, pain, and function in athletes with CLBP. Therefore, the current study aimed to investigate the effect of combining diaphragm training with electrical stimulation on balance, pain, and function in young athletes with non-specific CLBP.

\section{Methods}

\section{Design}

This single-blinded, randomized clinical trial was conducted between July 2019 and January 2020. This study was conducted based on the Guidelines for Consolidated Standards of Reporting Trials (CONSORT).

\section{Participants}

G*power 3 was used to calculate the sample size. The sample size of the 12 participants (including $20 \%$ dropout) in each group was capable of detecting a $20 \%$ difference in the single leg stance between the groups according to a similar study (19) assuming a standard deviation of $10 \%$, a significance level of 0.05 , and a power of $80 \%$.

A total of 24 athletes aged 20-35 years old were recruited from two outpatient rehabilitation clinics. Participants were included if they had intermittent non-specific CLBP at least for 12 weeks, with VAS between 3 to 7 , and training at least 3 sessions with 6 hours per week (20). Non-specific LBP is identified as LBP, which is not due to a known specific pathology (21). Participants were excluded if they had lumbar surgery experience, inflammatory spinal disease, spinal deformities, or neurologic radiating pain. Participants were also excluded from the study if they were unable to perform exercises. Participants were randomly assigned to the following two groups by block randomization method: TENS treatment or TENS plus diaphragm training (Fig. 1). Both groups underwent 12 intervention sessions over 4 weeks (3 sessions weekly).

The study procedure was clearly explained to all participants, and they signed written consent before entering into the study. The study was approved by the Research Ethics Committee at the Tehran University of Medical Sciences (IR.TUMS.FNM.REC.1398.138) and followed the principles of the Declaration of Helsinki. The trial was retrospectively registered at the Iranian Registry of Clinical Trials on www.irct.ir (Identification number: IRCT20090228001719N8).

\section{Outcome Measurements}

The following outcomes were collected by the examiner or self-report questionnaires.

\section{Pain}

Pain was assessed by the Numerical Rating Scale (NRS). The participants rated their pain on a defined 0-10 scale, where 0 is no pain, and 10 is the worst pain imaginable. NRS has different advantages, such as simplicity, reproducibility, easy comprehensibility, and sensitivity to small changes in pain (22).

\section{Function}

Core Outcome Measures Index (COMI) is a short, self-reported questionnaire for assessing important outcomes in patients with LBP. The COMI covers five different domains, with seven individual items; pain intensity (two separate items measuring back pain and leg/buttock pain), back function in everyday life (one item), symptom-specific well-being (one item), the general quality of life (one item) and disability (two separate items measuring social disability and work disability). The composite COMI score (range $0-10$ ) is calculated using the average score of the five domains. Higher COMI scores indicate worse status. For the domain pain intensity, the data are collected using 0-10 graphic rating scales, with the higher of the two values for back pain and leg/buttock pain being used to represent the "pain" domain. Five-point scales (1-5) are used for the remaining domains, with the scores being rescaled into a $0-10$ point range (score (1-5) minus 1 , multiplied by 2.5 ). 
The values for the two disability items are averaged to represent the "disability" domain. The average of the five domains form the COMI is $0-10$, best-worst (23).

\section{Static Stability}

Static stability was determined using the Unilateral Hip Bridge Endurance test (UHBE), which is a clinical measure of core stability (24). The UHBE test was performed with the participants lying supine with their arms across their chest, knees in flexion, and feet flat on the table. The participants performed a double-leg hip bridge, and once a neutral spine and pelvis position was achieved, the participants were instructed to extend one knee (randomly determined), so their leg was straight, and their thighs were parallel to another one. Participants were instructed to hold this position as long as possible. The test was terminated when they were no longer able to maintain a neutral pelvic position, as noted by a 10-degree change in transverse or sagittal plane alignment. Pelvic positioning in the transverse plane was monitored by a digital inclinometer attached to a mobilization belt that was tightly secured to the individual's pelvic (Fig. 2).

\section{Dynamic balance}

Star Excursion Balance Test (SEBT) was utilized to evaluate dynamic balance (25). The SEBT was accomplished while the participant was standing on the dominant leg and asked to reach as far as they could along a grid in the anterior, posteromedial, and posterolateral directions with the tip of the great toe of the non-stance limb. Participant's hands were held at the iliac crest during the test. Six practices followed by 2-min rest and three test trials were performed for each direction. The reaching distance of the grid was read and recorded manually, and the average of the three test trials was calculated. The order of reaching directions was randomized. The test was rejected and then repeated if a participant failed to maintain a unilateral stance, lifted or moved the standing foot from the grid, or failed to return the reaching limb to the starting position. For the assurance of accurate analysis, the data of the reaching distance was normalized by leg length to exclude the impact of the leg length. The leg length was measured from the anterior superior iliac spine most distal end to the most distal end of the lateral malleolus on each limb (26). Reaching in the anterior, posteromedial, and posterolateral directions have excellent reliability (27).

\section{Intervention}

All 24 participants completed the NRS, COMI, UHBT, and SEBT at baseline (before the intervention) and after completing the 4-week intervention. The control group received three sessions (30 min conventional TENS, impulse duration: $100 \mu \mathrm{s}$, frequency: $100 \mathrm{HZ}$ ) per week for 4 weeks (28). The experimental group received TENS plus diaphragm training for 12 sessions over a 4-week period. All participants in both group also received similar patient education information during the sessions. Breathing exercises were supervised by a physiotherapist at the beginning of each week to ensure that each breathing exercise was performed correctly. Participants were assigned two exercises a week and asked to complete each breathing exercise for 5 minutes, twice daily, for a total of 20 minutes a day at least 5 days per week. Instruction and feedback were given to participants on assessment days. When participants attended a clinic, breathing exercises were performed after electrotherapy with the therapist.

The exercises planned for each week were as follows:

\section{First week}

Supine breathing + Crocodile breathing

\section{Second week}

Supine breathing with TheraBand + Crocodile breathing with TheraBand

\section{Third week}

Seated breathing $+90 / 90 / 90$ breathing 


\section{Fourth week}

Seated breathing with TheraBand $+90 / 90 / 90$ breathing with TheraBand

\section{Supine Breathing}

Participants were instructed to lay supine in a hook-lying position and arms in a comfortable position. They were asked to focus on breathing with their diaphragm, the breath filling into their lower abdomen and posterior chest wall. They were asked to keep their ribs depressed and keep their shoulders and neck relaxed. During resisted exercise, TheraBand was added around the thoracolumbar junction or fixing by the therapist to a distal section of the bed to enhance resistance (Fig. 3a) (19).

\section{Crocodile breathing}

Participants were instructed to lay prone with their hands in a diamond shape supporting their forehead. They were asked to try and focus on pushing their ribs out laterally and trying to breathe all the way down to the sacrum. A TheraBand was placed under the participant's thoracolumbar junction during resistance training (Fig. 3b) (19).

Seated breathing: Participants were seated on a hard surface with their knees, hip, and ankles all at $90^{\circ}$. They were told to sit tall, as if a "string was pulling them up from the top of their head," while maintaining all previously discussed breathing cues: preventing lower rib flair, breathing deeply, and relaxing their shoulders, neck, and arms (Fig. 3c) (19).

90/90/90 breathing: Participants were placed in the 90/90/90 position and were asked to hold their legs while maintaining all previously discussed breathing cues: controlling their ribs and thoracolumbar junction, breathing deeply, and relaxing their shoulders, neck, and arms (Fig. 3d) (19). During resistance training, a TheraBand or belt was placed under the participant's thoracolumbar junction. The participant was instructed not to let the examiner pull the belt away. At home, participants were instructed to tie the TheraBand around a table or chair and leave tension in it to simulate the effect of pulling.

\section{Statistical analysis}

Data analysis was performed using SPSS version 22.0 (SPSS Inc., Chicago, IL, USA). Normal distribution of data was confirmed by the Shapiro-Wilk test and graphical assessment. Paired t-test was used to evaluate within-group changes from baseline to the final assessment for each participant. Independent t-test was also used to compare the two groups. The statistical significance level was set as $a=0.05$. The effect size was assessed by Cohen's $d$ effect size.

\section{Results}

The characteristics of the participants in each group are shown in Table 1. There were no significant differences between the groups at baseline.

Table 1

Demographic characteristics of participants.

\begin{tabular}{|lll|}
\hline Variable & $\begin{array}{l}\text { Control } \\
(\mathrm{n}=12)\end{array}$ & $\begin{array}{l}\text { Experimental } \\
(\mathrm{n}=12)\end{array}$ \\
\hline Gender & 7 female, 5 male & 5 female, 7 male \\
\hline Age (year) & $20.3 \pm 8.1$ & $20.4 \pm 9.8$ \\
\hline Height $(\mathrm{m})$ & $1.7 \pm 0.6$ & $1,7 \pm 0.1$ \\
\hline Weight $(\mathrm{kg})$ & $65.1 \pm 25.7$ & $66.2 \pm 27.8$ \\
\hline BMI $\left(\mathrm{kg} / \mathrm{m}^{2}\right)$ & $24.9 \pm 3.1$ & $25.8 \pm 5.7$ \\
\hline
\end{tabular}

Page 5/14 


\section{Pain and function measures}

The within-group analysis showed significant improvements in pain (NRS) and function (COMI) after the 4-week intervention in both groups. Comparing the groups revealed a greater decrease in pain with a large effect size in the experimental group $(E F=1.3, p<0.01)$. No significant difference was found between the groups regarding the function (Table 2).

Table 2

Comparison of the pre-intervention and post-intervention pain and function results.

\begin{tabular}{|c|c|c|c|c|c|c|c|c|c|}
\hline \multirow[t]{2}{*}{ Variable } & \multirow[t]{2}{*}{ Group } & \multirow[t]{2}{*}{ Pre- intervention } & \multirow[t]{2}{*}{ Post-intervention } & \multicolumn{3}{|c|}{ Within-group } & \multicolumn{3}{|c|}{ Between-group } \\
\hline & & & & $t$ & $\mathrm{p}$-value & ES & $t$ & $\mathrm{p}$-value & ES \\
\hline \multirow{2}{*}{$\begin{array}{l}\text { Pain } \\
\text { (NRS) }\end{array}$} & TENS & $4.7 \pm 1.3$ & $3.1 \pm 1.3$ & 5.2 & 0.001 & 1.2 & \multirow[t]{2}{*}{2.9} & \multirow[t]{2}{*}{0.01} & \multirow[t]{2}{*}{1.3} \\
\hline & TENS + DT & $5.5 \pm 1.1$ & $1.7 \pm 0.6$ & 9.7 & 0.001 & 4 & & & \\
\hline \multirow{2}{*}{$\begin{array}{l}\text { Function } \\
\text { (COMI) }\end{array}$} & TENS & $4.5 \pm 0.9$ & $2.6 \pm 0.6$ & 9.1 & 0.001 & 2.3 & \multirow[t]{2}{*}{1.74} & \multirow[t]{2}{*}{0.09} & \multirow[t]{2}{*}{0.1} \\
\hline & TENS + DT & $4.5 \pm 0.7$ & $1.9 \pm 0.9$ & 6.8 & 0.001 & 2.8 & & & \\
\hline
\end{tabular}

TENS: Trans Cutaneous Electrical Nerve Stimulation; DT: Diaphragm training; COMI: Core Outcome Measure Index; NRS: Numeric Rating Scale, ES: Effect Size.

\section{Static stability and dynamic balance}

Comparisons of static stability (UHBE test) for pre- and post-intervention revealed significant improvements on both sides only in the experimental group. Significant differences in the static stability were found $(p=0.04)$ between the groups on both sides with effect sizes of 0.96 and 0.95 , respectively (Table 3). Dynamic balance (SEBT test) significantly improved in all directions after the intervention compared to the pre-intervention only in the experimental group $(p<0.05)$. However, there was no significant difference between the groups regarding the dynamic balance (Table 3). 
Table 3

Comparison in static and dynamic balance indices within and between the groups.

\begin{tabular}{|c|c|c|c|c|c|c|c|c|c|c|c|}
\hline \multirow{2}{*}{\multicolumn{2}{|c|}{ Variable }} & \multirow[t]{2}{*}{ Side } & \multirow[t]{2}{*}{ Group } & \multirow{2}{*}{$\begin{array}{l}\text { Pre- } \\
\text { intervention }\end{array}$} & \multirow{2}{*}{$\begin{array}{l}\text { Post- } \\
\text { intervention }\end{array}$} & \multicolumn{3}{|c|}{ Within-group } & \multicolumn{3}{|c|}{ Between-group } \\
\hline & & & & & & $\mathrm{t}$ & $\begin{array}{l}\mathrm{p}- \\
\text { value }\end{array}$ & ES & $\mathrm{t}$ & $\begin{array}{l}\mathrm{p}- \\
\text { value }\end{array}$ & ES \\
\hline \multirow{4}{*}{\multicolumn{2}{|c|}{ Static stability }} & Rt & \multirow[t]{2}{*}{ TENS } & $25.9 \pm 11.5$ & $27.3 \pm 11.5$ & 0.72 & 0.4 & 0.12 & \multirow{2}{*}{$\begin{array}{l}\text { Lt: } \\
-2.14\end{array}$} & \multirow[t]{2}{*}{0.04} & \multirow[t]{2}{*}{0.95} \\
\hline & & Lt & & $25.1 \pm 11.1$ & $28.3 \pm 13.7$ & -1.91 & 0.09 & 0.26 & & & \\
\hline & & Rt & \multirow[t]{2}{*}{$\begin{array}{l}\text { TENS } \\
+ \text { + DT }\end{array}$} & $\begin{array}{l}26.3 \pm \\
11.09\end{array}$ & $37.5 \pm 12.6$ & -2.41 & 0.03 & 0.94 & \multirow{2}{*}{$\begin{array}{l}\text { Rt: } \\
-2.12\end{array}$} & \multirow[t]{2}{*}{0.04} & \multirow[t]{2}{*}{0.96} \\
\hline & & Lt & & $25 \pm 10.1$ & $40.1 \pm 10.6$ & -10.5 & 0.001 & 1.46 & & & \\
\hline \multirow{16}{*}{$\begin{array}{l}\text { Dynamic } \\
\text { Balance }\end{array}$} & \multirow[t]{4}{*}{ Ant } & Rt & \multirow[t]{2}{*}{ TENS } & $81.8 \pm 9.82$ & $\begin{array}{l}82.35 \pm \\
10.7\end{array}$ & -4.45 & 0.2 & 0.4 & \multirow{2}{*}{$\begin{array}{l}\text { Rt: } \\
-2.2\end{array}$} & \multirow[t]{2}{*}{0.3} & \multirow[t]{2}{*}{1} \\
\hline & & Lt & & $82.2 \pm 10.6$ & $83.8 \pm 10.7$ & -5.46 & 0.1 & 0.43 & & & \\
\hline & & Rt & \multirow{2}{*}{$\begin{array}{l}\text { TENS } \\
+\mathrm{DT}\end{array}$} & $80.1 \pm 7.1$ & $87.7 \pm 7.9$ & -10.7 & 0.02 & 2.07 & Lt: & \multirow[t]{2}{*}{0.9} & \multirow[t]{2}{*}{0.02} \\
\hline & & Lt & & $81.7 \pm 7.8$ & $86.3 \pm 8.3$ & -11.33 & 0.001 & 0.94 & 0.1 & & \\
\hline & Post & Rt & \multirow[t]{2}{*}{ TENS } & $76.4 \pm 13.1$ & $82.1 \pm 14.6$ & -2.13 & 0.06 & 0.4 & Rt: & \multirow[t]{2}{*}{0.09} & \multirow[t]{2}{*}{0.8} \\
\hline & \multirow[t]{3}{*}{ Lat } & Lt & & $76.9 \pm 14.5$ & $78.7 \pm 14.1$ & -0.63 & 0.07 & 0.12 & -1.8 & & \\
\hline & & Rt & \multirow{2}{*}{$\begin{array}{l}\text { TENS } \\
+ \text { DT }\end{array}$} & $71.5 \pm 7.68$ & $91.5 \pm 8.3$ & -5.97 & 0.001 & 2.5 & Lt: & \multirow[t]{2}{*}{0.7} & \multirow[t]{2}{*}{0.15} \\
\hline & & Lt & & $69.7 \pm 7.1$ & $76.9 \pm 8.6$ & -5.9 & 0.001 & 0.9 & 0.3 & & \\
\hline & Post & Rt & TENS & $83.2 \pm 14.9$ & $85.5 \pm 14.3$ & -.74 & 0.5 & 0.16 & Rt: & 0.06 & 1.06 \\
\hline & Med & Lt & & $83.4 \pm 13.8$ & $88.7 \pm 17.8$ & -2.26 & 0.06 & 0.33 & -2.57 & & \\
\hline & & Rt & TENS & $79.5 \pm 7.3$ & $98.1 \pm 8.7$ & -11.12 & 0.001 & 2.3 & Lt: & 0.4 & 0.33 \\
\hline & & $\mathrm{Lt}$ & & $77.1 \pm 8.4$ & $83.9 \pm 10.1$ & -5.83 & 0.001 & 0.73 & 0.7 & & \\
\hline & Total & Rt & TENS & $80.5 \pm 12.5$ & $88.6 \pm 13$ & -1.9 & 0.08 & 0.63 & Rt: & 0.07 & 0.7 \\
\hline & & Lt & & $80.7 \pm 12.8$ & $82.7 \pm 13.8$ & -2.48 & 0.06 & 0.3 & -2.3 & & \\
\hline & & Rt & TENS & $77.1 \pm 6.8$ & $95.1 \pm 7.5$ & -16.4 & 0.001 & 2.5 & Lt: & 0.6 & 0.2 \\
\hline & & Lt & & $75.4 \pm 7.3$ & $82.4 \pm 8.8$ & -7.2 & 0.001 & 0.86 & 0.5 & & \\
\hline
\end{tabular}

TENS: Trans Cutaneous Electrical Nerve Stimulation; DT: Diaphragm training; ES: Effect Size; Rt: Right; Lt: Left; Ant: Anteior; PostLat: Posterior lateral; PostMed: Posterior medial.

\section{Discussion}

In this study, we investigated whether adding diaphragm training to electrical stimulation may improve static stability balance, function, and pain in young adult athletes with non-specific CLBP. The main findings showed that the experimental group (diaphragm training plus TENS) was superior in reducing pain and improving static stability after a 12-session intervention compared to the control group (TENS). Whereas, function and dynamic balance were comparable between the groups. 
Both groups showed significantly reduced pain after undergoing 12 intervention sessions compared to the pre-intervention scores. However, the reduction of pain in the experimental group was greater than the control group (larger effect size). A $30 \%$ change in pain score from baseline is clinically significant for individual patients with LBP (29). The reduction was approximately $34 \%$ and $69 \%$ in the control and experimental group, respectively. The pain reduction supports the previous studies. The positive effect of TENS on the reduction of pain in participants with CLBP was concluded by one systematic review (30). Likewise, other researchers found that sensory electrical stimulation had a greater effect than other currents on reducing pain (28). The reduction in pain can be due to the local effect of electrical currents on the nociceptor of the lumbar region as well as the reduction of back muscle spasm $(28,30)$. However, a greater reduction of pain in the experimental group with an effect size of 1.3 could be due to the effects of diaphragm training. The diaphragm is the primary muscle of inspiration but also involves in trunk stability and control of posture as part of the core muscles (12). Accordingly, previous studies have shown that breathing exercise can reduce pain in LBP due to increased stability of the trunk as well as reduced tension in other central muscles of the body, especially the multifidus muscle $(8,10)$. Janssens et al. $(2015)$ reported that an 8-week high-intensity inspiratory muscle training, albeit not low-intensity, could be effective in reducing pain and increasing respiratory function in patients with CLBP (11). Deep breathing exercise can also lead to significant changes in respiratory function and core muscle activation during breathing in $\operatorname{CLBP}(31,32)$. Therefore, adding breathing exercise to electrotherapy in rehabilitation programs may lead to more pain relief in athletes with CLBP.

\section{Function}

The quality and function of daily activities measured by the COMI revealed significant improvements after completing 12 intervention sessions in both groups; however, there was no significant difference between the two groups. COMI-back is a reliable, valid, and brief instrument to assess pain intensity, function, symptom-specific well-being, disability, and general quality of life in patients with back problems $(33,34)$. Some questions of the COMI questionnaire are related to the quality of life, performance, and satisfaction of patients with LBP; therefore, psychological situations may affect the COMI score (35). In this study, most of the participants reported a reduction of pain; therefore, they could return to their daily activities, and they answered the questions in COMI positively. In line with our results, previous studies have reported the positive effect of electrotherapy (e.g., TENS) on reducing disability in patients with CLBP measured by the Roland Morris questionnaire (28, 36). Therefore, a reduction in pain can affect the patient's psychological and physical aspects and may improve the quality of life of participants in both groups. As mentioned before, diaphragm training may increase diaphragm muscle strength and respiratory capacity, and improve the stability of the spine, thereby daily function in healthy individuals and patients with lumbar instability $(19,32,37,38)$. Mehling et al. (2005) reported significant improvements in function and pain with 68 weeks of breathing exercise compared to conventional physical therapy in patients with CLBP (10). Regarding the nonsignificant between-group comparison $(p=0.09)$, it may be possible that with a greater sample size, the results would show a significant difference between the groups.

\section{Stability and Balance}

After a 4-week intervention, static stability assessed by the UHBE test showed improvements for both limbs only in the experimental group. In addition, the experimental group had better post-intervention stability scores for both legs compared to the control group. This finding indicates that diaphragm training can lead to improved static stability. In agreement with our results, Stephens et al. (2017) also found improvement in static balance after an 8-week training in diaphragmatic breathing in healthy individuals.

The diaphragm is one of the core muscles, which stabilize the trunk and spine; these muscles act as one unit at the center of functional kinetic chains and activities of upper and lower limbs, especially sports activities (16).

Increasing the stability of the trunk may consequently improve a person's balance. However, regarding the dynamic balance assessed by SEBT, an improved dynamic balance was found only in the experimental group for both limbs and all directions. This finding could result from the effects of diaphragm training because it may positively affect intra-abdominal pressure, abdominal endurance, and movement efficiency, which, in turn, may improve dynamic balance performance in the 
experimental group (39). In addition, diaphragm training may enhance the activity of other core muscles; for example, Cho (2019) showed crocodile breathing is a good method for improving the multifidus muscle activity in patients with LBP (40). Increasing the stability of the body's core and more stability in the waist and pelvis can lead to improved balance in the lower limbs and even upper limb movements.

\section{Limitations}

some limitations should be considered while interpreting the findings of this study. A lack of a group with only diaphragm training. In addition, the sample of young athletes with CLBP limits the generalizability of the results to other age groups and non-athlete patients. A lack of follow-up assessment is another limitation. Therefore, future studies are needed to investigate the effects of diaphragm training alone and in different sample populations.

\section{Conclusion}

In general, this study suggests that diaphragm training plus TENS for 12 sessions can reduce not only pain but also improve function, static stability and dynamic balance in young adult athletes with non-specific CLBP. Moreover, diaphragm training plus TENS is superior in reducing pain and improving static stability than only TENS. Therefore, it seems beneficial to add diaphragm training to the rehabilitation program for athletes with non-specific CLBP.

\section{Declarations}

\section{Ethics approval and consent to participate}

All participants signed a consent form, and the study was approved by the Human Ethics Committee at Tehran University of Medical Sciences, Tehran, Iran (IR.TUMS.FNM.REC.1398.138).

\section{Consent for publication}

Written informed consent was obtained from the participants for publication of their individual details and accompanying images in this manuscript. The consent form is held by the first author and is available for review by the Editor-in-Chief.

\section{Availability of data and materials}

The datasets generated and analyzed during the current study are available from the corresponding author upon request.

\section{Competing interests}

The authors declare that they have no competing interests.

\section{Funding}

This study was supported by the School of Rehabilitation at Tehran University of Medical Sciences.

\section{Authors' contributions}

$\mathrm{KO}$ and SS were responsible for the study design. SS and AA collected and prepared the data. KO and HS analyzed the data. $\mathrm{OR}$ and $\mathrm{KO}$ were responsible for writing and redrafting the manuscript. All authors read and approved the final manuscript.

\section{Acknowledgment}

The authors would like to thank all participants. 


\section{References}

1. Bono CM. Low-back pain in athletes. J Bone Joint Surg Am. 2004;86(2):382-96.

2. Trompeter K, Fett D, Platen P. Prevalence of Back Pain in Sports: A Systematic Review of the Literature. Sports Med. 2017;47(6):1183-207.

3. Huxel Bliven KC, Anderson BE. Core stability training for injury prevention. Sports Health. 2013;5(6):514-22.

4. Kibler WB, Press J, Sciascia A. The role of core stability in athletic function. Sports Med. 2006;36(3):189-98.

5. Calvo-Lobo C, Almazan-Polo J, Becerro-de-Bengoa-Vallejo R, Losa-Iglesias ME, Palomo-Lopez P, Rodriguez-Sanz D, et al. Ultrasonography comparison of diaphragm thickness and excursion between athletes with and without lumbopelvic pain. Phys Ther Sport. 2019;37:128-37.

6. Swain CTV, Bradshaw EJ, Whyte DG, Ekegren CL. Life history and point prevalence of low back pain in pre-professional and professional dancers. Phys Ther Sport. 2017;25:34-8.

7. Kocjan J, Adamek M, Gzik-Zroska B, Czyżewski D, Rydel M. Network of breathing. Multifunctional role of the diaphragm: a review. Advances in respiratory medicine. 2017;85(4):224-32.

8. Janssens L, Brumagne S, McConnell AK, Hermans G, Troosters T, Gayan-Ramirez G. Greater diaphragm fatigability in individuals with recurrent low back pain. Respir Physiol Neurobiol. 2013;188(2):119-23.

9. Finta R, Nagy E, Bender T. The effect of diaphragm training on lumbar stabilizer muscles: a new concept for improving segmental stability in the case of low back pain. J Pain Res. 2018;11:3031-45.

10. Mehling WE, Hamel KA, Acree M, ByI N, Hecht FM. Randomized, controlled trial of breath therapy for patients with chronic low-back pain. Altern Ther Health Med. 2005;11(4):44-52.

11. Janssens L, McConnell AK, Pijnenburg M, Claeys K, Goossens N, Lysens R, et al. Inspiratory muscle training affects proprioceptive use and low back pain. Med Sci Sports Exerc. 2015;47(1):12-9.

12. Celhay I, Cordova R, Miralles R, Meza F, Erices P, Barrientos C, et al. Effect of upper costal and costo-diaphragmatic breathing types on electromyographic activity of respiratory muscles. Cranio. 2015;33(2):100-6.

13. Kolář P, Šulc J, Kynčl M, Šanda J, Čakrt O, Andel R, et al. Postural function of the diaphragm in persons with and without chronic low back pain. J Orthop Sports Phys Ther. 2012;42(4):352-62.

14. Sarah J, Lisman P, Gribbin TC, Murphy K, Deuster PA. Systematic review of the association between physical fitness and musculoskeletal injury risk: part 3-flexibility, power, speed, balance, and agility. The Journal of Strength Conditioning Research. 2019;33(6):1723-35.

15. Hibbs AE, Thompson KG, French D, Wrigley A, Spears I. Optimizing performance by improving core stability and core strength. Sports Med. 2008;38(12):995-1008.

16. Akuthota V, Ferreiro A, Moore T, Fredericson M. Core stability exercise principles. Curr Sports Med Rep. 2008;7(1):39-44.

17. Hayden JA, van Tulder MW, Malmivaara A, Koes BW. Exercise therapy for treatment of non-specific low back pain. Cochrane Database Syst Rev. 2005(3):CD000335.

18. Sayilir S, Yildizgoren MT. The medium-term effects of diadynamic currents in chronic low back pain; TENS versus diadynamic currents: A randomised, follow-up study. Complement Ther Clin Pract. 2017;29:16-9.

19. Stephens RJ, Haas M, Moore WL 3rd, Emmil JR, Sipress JA, Williams A. Effects of Diaphragmatic Breathing Patterns on Balance: A Preliminary Clinical Trial. J Manipulative Physiol Ther. 2017;40(3):169-75.

20. Koes BW, van Tulder M, Lin CW, Macedo LG, McAuley J, Maher C. An updated overview of clinical guidelines for the management of non-specific low back pain in primary care. Eur Spine J. 2010;19(12):2075-94.

21. Maher C, Underwood M, Buchbinder R. Non-specific low back pain. Lancet. 2017;389(10070):736-47.

22. Gerbershagen HJ, Rothaug J, Kalkman CJ, Meissner W. Determination of moderate-to-severe postoperative pain on the numeric rating scale: a cut-off point analysis applying four different methods. Br J Anaesth. 2011;107(4):619-26. 
23. Komesh S, Nakhostin Ansari N, Naghdi S, Alaei P, Hasson S, Kordi R. Responsiveness and longitudinal validity of the Persian version of COMI to physiotherapy in patients with non-specific chronic low back pain. Scand J Pain. 2020;20(3):483-90.

24. Butowicz CM, Ebaugh DD, Noehren B, Silfies SP. Validation of Two Clinical Measures of Core Stability. Int J Sports Phys Ther. 2016;11(1):15-23.

25. Ganesh GS, Chhabra D, Mrityunjay K. Efficacy of the star excursion balance test in detecting reach deficits in subjects with chronic low back pain. Physiother Res Int. 2015;20(1):9-15.

26. Imai A, Kaneoka K, Okubo Y, Shiraki H. Effects of two types of trunk exercises on balance and athletic performance in youth soccer players. Int J Sports Phys Ther. 2014;9(1):47-57.

27. Lauenroth A, Reinhardt L, Schulze S, Laudner KG, Delank K-S, Schwesig R. Does low back pain affect the reliability of postural regulation? Somatosens Mot Res. 2019;36(2):116-21.

28. Rajfur J, Pasternok M, Rajfur K, Walewicz K, Fras B, Bolach B, et al. Efficacy of Selected Electrical Therapies on Chronic Low Back Pain: A Comparative Clinical Pilot Study. Med Sci Monit. 2017;23:85-100.

29. Ostelo RW, Deyo RA, Stratford P, Waddell G, Croft P, Von Korff M, et al. Interpreting change scores for pain and functional status in low back pain: towards international consensus regarding minimal important change. Spine (Phila Pa 1976). 2008;33(1):90-4.

30. Khadilkar A, Milne S, Brosseau L, Wells G, Tugwell P, Robinson V, et al. Transcutaneous electrical nerve stimulation for the treatment of chronic low back pain: a systematic review. Spine (Phila Pa 1976). 2005;30(23):2657-66.

31. Kim E, Lee $\mathrm{H}$. The effects of deep abdominal muscle strengthening exercises on respiratory function and lumbar stability. J Phys Ther Sci. 2013;25(6):663-5.

32. Anderson $\mathrm{BE}$, Bliven $\mathrm{KCH}$. The use of breathing exercises in the treatment of chronic, nonspecific low back pain. Journal of sport rehabilitation. 2017;26(5):452-8.

33. Nakhostin Ansari N, Naghdi S, Eskandari Z, Salsabili N, Kordi R, Hasson S. Reliability and validity of the Persian adaptation of the Core Outcome Measure Index in patients with chronic low back pain. J Orthop Sci. 2016;21(6):723-6.

34. Mannion AF, Porchet F, Kleinstuck FS, Lattig F, Jeszenszky D, Bartanusz V, et al. The quality of spine surgery from the patient's perspective. Part 1: the Core Outcome Measures Index in clinical practice. Eur Spine J. 2009;18(Suppl 3(3):367-73.

35. Mannion AF, Vila-Casademunt A, Domingo-Sabat M, Wunderlin S, Pellise F, Bago J, et al. The Core Outcome Measures Index (COMI) is a responsive instrument for assessing the outcome of treatment for adult spinal deformity. Eur Spine J. 2016;25(8):2638-48.

36. Facci LM, Nowotny JP, Tormem F, Trevisani VF. Effects of transcutaneous electrical nerve stimulation (TENS) and interferential currents (IFC) in patients with nonspecific chronic low back pain: randomized clinical trial. Sao Paulo Med J. 2011;129(4):206-16.

37. Kang J-Y, Seo D-K, Cho J-C, Lee B-K. Effectiveness of Breathing Exercises on Spinal Posture, Mobility and Stabilization in Patients with Lumbar Instability. Korean Society of Physical Medicine. 2018;13(3):81-9.

38. Ki C, Heo M, Kim HY, Kim EJ. The effects of forced breathing exercise on the lumbar stabilization in chronic low back pain patients. J Phys Ther Sci. 2016;28(12):3380-3.

39. Cavaggioni L, Ongaro L, Zannin E, laia FM, Alberti G. Effects of different core exercises on respiratory parameters and abdominal strength. J Phys Ther Sci. 2015;27(10):3249-53.

40. Cho Y-H. The Effects of the Crocodile Breathing Exercise on the Muscle Activity of the Erector Spinae Muscle in Patients with Low Back Pain. PNF Movement. 2019;17(2):321-7.

\section{Figures}




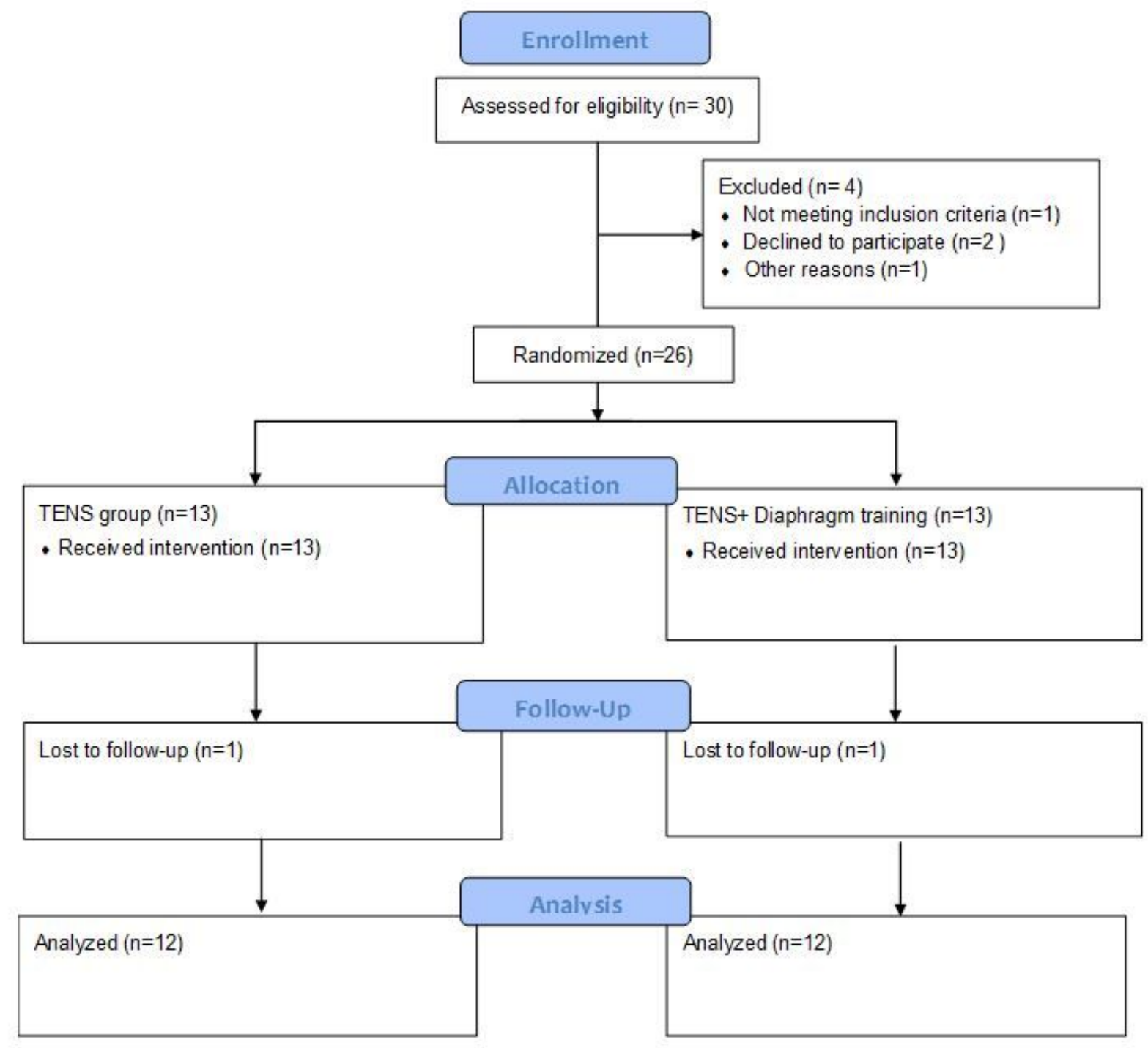

\section{Figure 1}

Flow diagram of included participants. 


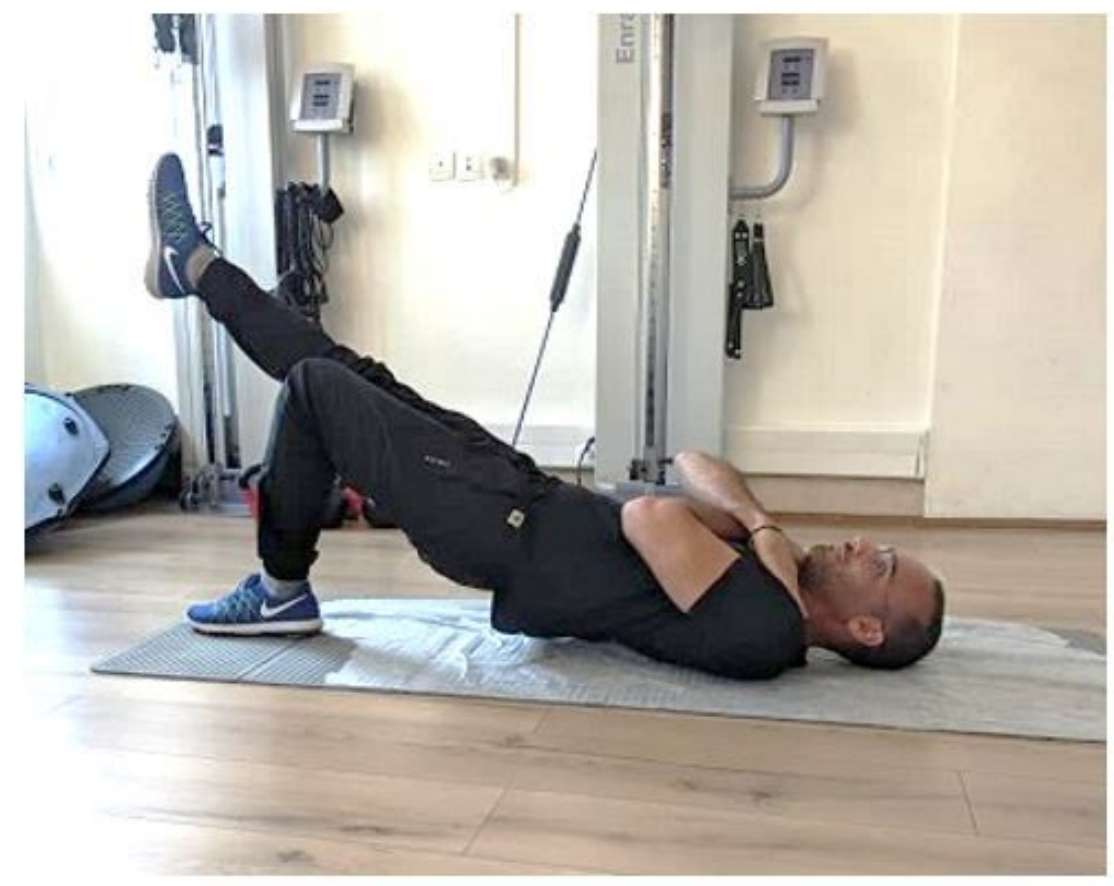

Figure 2

Unilateral Hip Bridge Endurance test (UHBE). 

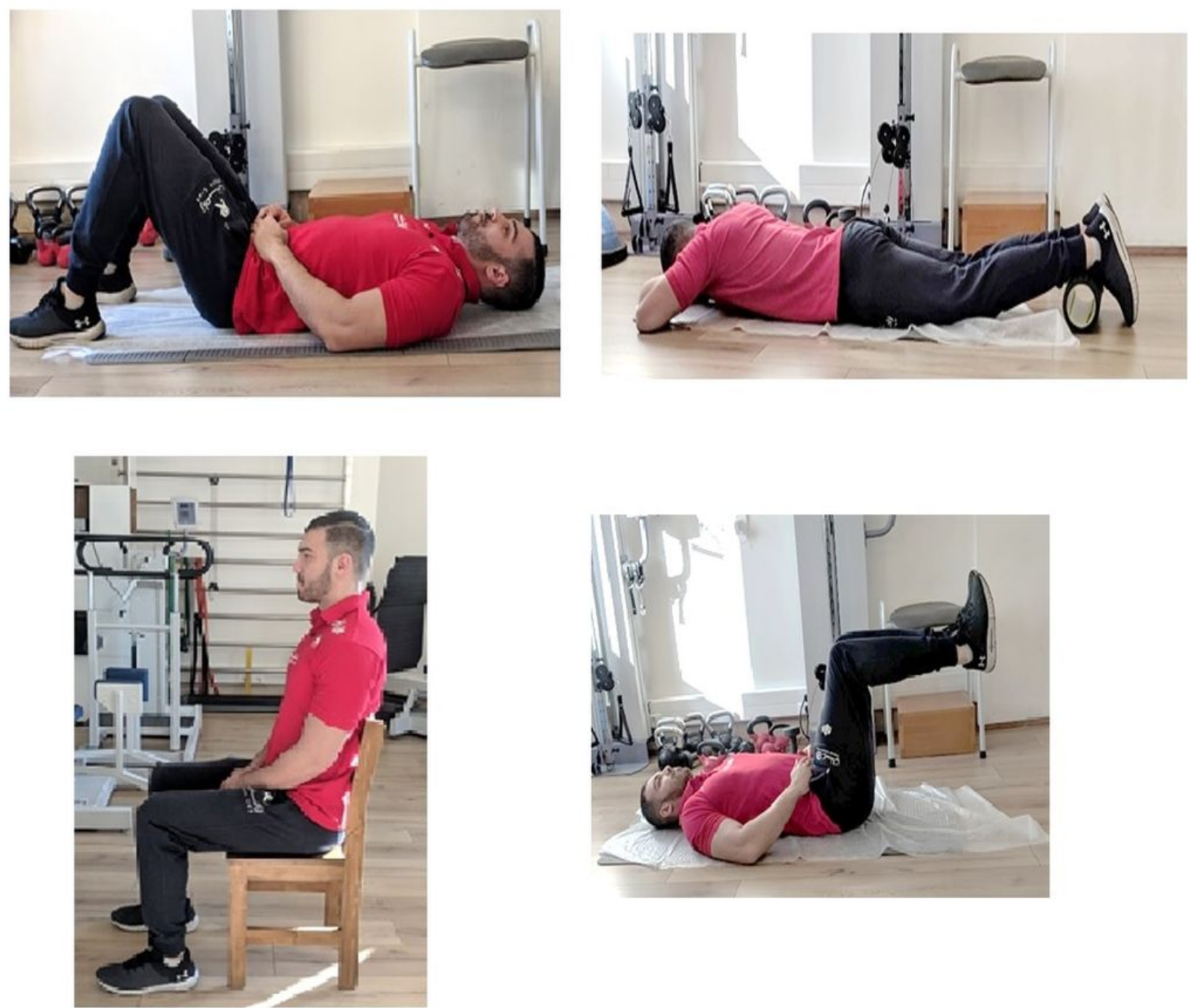

\section{Figure 3}

3a. Supine Breathing. 3b. Crocodile breathing. 3c. Seated breathing. 3d. 90/90/90 breathing. 